\title{
Research on the effect of the charge diameter on the slow cook-off performance of HMX base explosive
}

\author{
Yang Jian', Jin Penggang ${ }^{2}$, Li Hongbin ${ }^{3}$, Ren Songtao ${ }^{4}$ \\ Xi'an Institute of Modern Chemistry, Xi'an, China \\ ${ }^{2}$ Corresponding author \\ E-mail: ${ }^{1}$ yangj22@163.com, ${ }^{2}$ jinpenggang204@126.com, ${ }^{3}$ lihongbin6868@163.com, \\ 4rensongtao@163.com
}

Received 12 May 2021; received in revised form 28 May 2021; accepted 5 June 2021 DOI https://doi.org/10.21595/vp.2021.22049

Check for updates

Copyright (C) 2021 Yang Jian, et al. This is an open access article distributed under the Creative Commons Attribution License, which permits unrestricted use, distribution, and reproduction in any medium, provided the original work is properly cited.

\begin{abstract}
In order to study the effect of the charge diameter on the slow cook-off (SCO) performance of HMX (cyclotetramerthylenetetranitramine) based explosives, a typical cyclotetramerthylenetetranitramine based explosive was used as the research object, and the effect of the different charge diameters on the slow cook-off performance was studied. The research results show that: the charge diameter has no significant effect on the response level of the cyclotetramerthylenetetranitramine based explosives. The reaction time and ambient temperature increase with the increase of the charge diameter, and the center temperature decreases with the increase of the charge diameter. The ambient temperature and the center temperature change regularly with the increase of the charge diameter.
\end{abstract}

Keywords: charge diameter, cyclotetramerthylenetetranitramine based explosives, slow cook-off.

\section{Introduction}

After the concept of low vulnerabilityammunition (LOVA) was proposed in 1973, its related research has been highly followed with interest by countries all over the world and has become an important theme of international conferences [1-4]. Therefore, the United States has formulated the MIL-STD-2105D standard for assessment hazard of non-nuclear munitions, which includes fast cook-off/FCO test and slow cook-off test/SCO. Slow cook-off test is used to evaluate the heat sensitivity and the severity of the reaction of explosives and other energetic materials under slowness heating conditions. It is mainly designed for unexpected thermal stimuli in the manufacturing, storage, transportation and application environments. Sehoites J. H. G studied the HTPB/AP, PPG/AP/AN propellant's burning test [5]. Kondrikov B. N. studied three kinds of cookoff test devices and related test procedures [6]. Wang Xiao-feng etc. studied cook-off test methods and cook-off results of booster explosives [7]. Feng Chang-gen took the RDX explosives as the research object, studied the cook-off experiments and the numerical simulations, and reached a conclusion consistent with the thermal explosion theory [8]. Yang Li-xia et al. established a fast cook-off equipment and slow cook-off equipment, and studied the vulnerability response performance and influencing factors with typical propellant as the object [9]. However, the studies are focused on the small charges' diameter, which cannot fully reflect the slow cook-off performance of explosives under the condition of large charge. The effect of the charge diameter on the slow cook-off performance of explosives, especially the effect on the cyclotetramerthylenetetranitramine base explosives is rarely reported. Therefore, the systematic study of the effect of the charge diameter on the slow cook-off response temperature and response level of cyclotetramerthylenetetranitramine based explosives is useful for predicting the thermal safety of the cyclotetramerthylenetetranitramine based explosive. 


\section{Test device and test method}

\subsection{Test device}

The test device is a self-developed slow cook-off system, which is mainly composed of a heating jacket, a temperature control box, a control computer, temperature sensors, and thermal insulation materials. It can measure 4 temperature data at the same time, and the maximum mass of simple can reach 20 kilograms, as shown in Fig. 1. The heating jacket is customized according to the sample size, and the heating power is adjustable from 400 to $4000 \mathrm{~W}$. The temperature control box is composed of temperature control instruments, display instruments and power adjustment modules. According to needs, the control computer sets different PID parameters to control the heating speed, temperature control accuracy can reach $\pm 0.2^{\circ} \mathrm{C} / \mathrm{min}$. the control computer can set and control the heating process of the temperature controller, record the temperature-time curve of the experiment, and draw the temperature-time curve. The environment during the temperature sensors measurement experiment and the temperature of the center of the sample, the accuracy grade is level one. The insulation material is wrapped on the outer surface of the test tube to reduce the heat loss during the test.

The test tube is made of $45 \#$ steel, as shown in Fig. 2. The wall thickness of the test tube is $4 \mathrm{~mm}$, and the internal dimensions are respectively $\varphi 20 \times 80, \varphi 60 \times 240, \varphi 97.5 \times 400, \varphi 148 \times 600$. Both ends are sealed with threaded end caps of the same thickness, and one end cap has $\varphi_{2}$ through holes in the center to install temperature sensor.

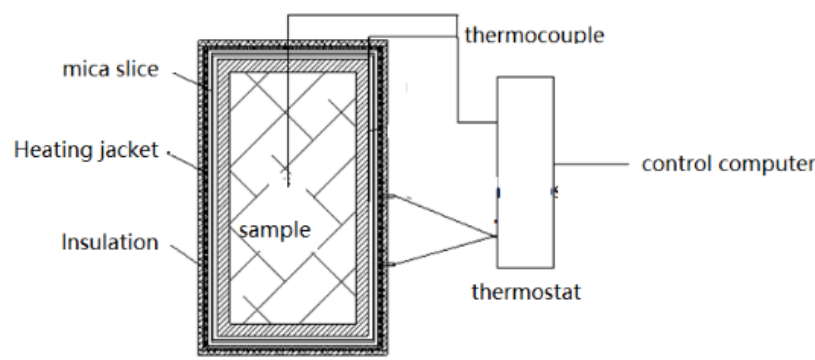

Fig. 1. Layout of slow cook-off device

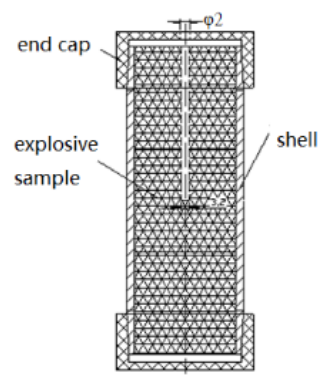

Fig. 2. Schematic diagram of test tube

\subsection{Test methods and test conditions}

A typical cyclotetramerthylenetetranitramine based bonded explosive (HMX: binder $=95: 5)$ was pressed into $\varphi 20 \times 20, \varphi 60 \times 60, \varphi 97.5 \times 100$, and $\varphi 148 \times 100$ column, with a density of $1.73 \mathrm{~g} / \mathrm{cm}^{3}$. Load the columns into the $\varphi 20 \times 80, \varphi 60 \times 240, \varphi 97.5 \times 400, \varphi 148 \times 600$ test tubes; a thermocouple is fixed at the center of the outer wall of the tube to measure the temperature at the center of the outer wall of the tube (referred as ambient temperature), another thermocouple is fixed in the center of the charge to measure the temperature at the center of the charge (referred as center temperature). The holes on the end caps are sealed with high temperature resistant sealant and the test tube are insulated and keep warm. As shown in Fig. 1. Prepare two samples of the same charge diameter for parallel experiment.

Hang the processed sample on a special steel support, and place a galvanized iron sheet as a witness board in the three directions around the sample and $1 \mathrm{~m}$ away from the sample. Install video surveillance in the direction where the witness board is not placed, as shown in Fig. 3; during the test, the sample is heated at a heating rate of $1{ }^{\circ} \mathrm{C} / \mathrm{min}$, and stop heating until the sample reacts or the temperature reaches $400{ }^{\circ} \mathrm{C}$, and use the computer to track and record temperatures of the center of the outer wall of the tube and the center of the charge; the hard disk video recorder is used to shoot the response of the samples. The response level is measured according to the deformation and fragments of the tube and witness plates. The typical temperature-time curve of 
the slow cook-off test is shown in Fig. 4 and Fig. 5.
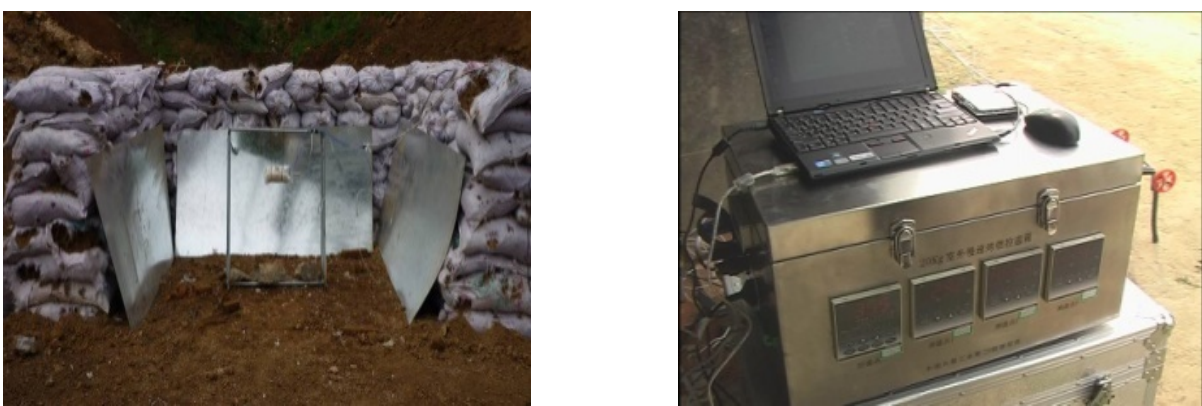

Fig. 3. Layout of Slow cook-off test
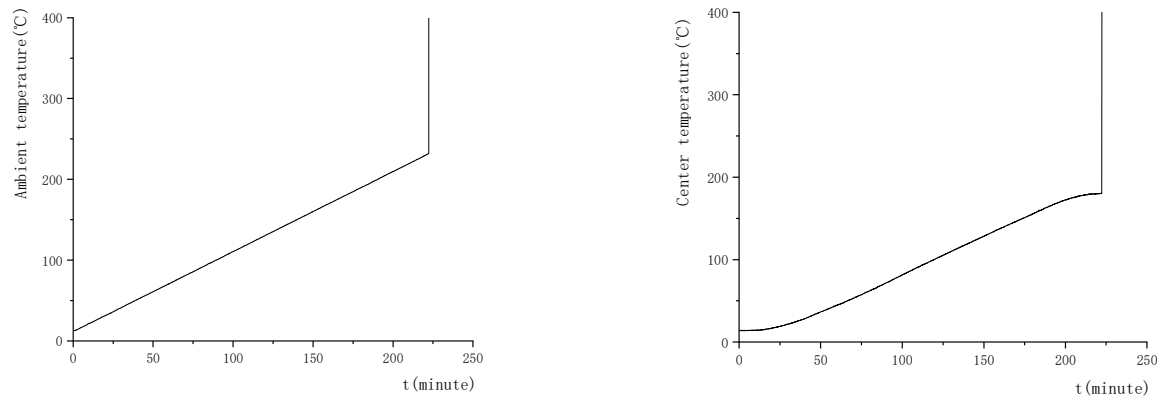

Fig. 4. Ambient temperature-time curve of SCO test Fig. 5. Center temperature-time Curve of SCO test

\section{Results and discussion}

\subsection{Test results}

Fit the temperature of the ambient temperature-time data collected by the computer using the least square method to obtain the heating rate during the test of different charge diameter samples, which is used to calibrate the heating rate during the test. As shown in Table 1.

Table 1. Fitting parameters of heating rate

\begin{tabular}{|c|c|}
\hline Charge diameter $(\mathrm{mm})$ & Heating rate of fitting $\left({ }^{\circ} \mathrm{C} \cdot \mathrm{min}^{-1}\right)$ \\
\hline 20 & 0.99 \\
\hline 60 & 1.01 \\
\hline 97.5 & 0.98 \\
\hline 148 & 1.00 \\
\hline
\end{tabular}

The results from the Table 1 show that the heating rate is controlled within $1 \pm 0.02{ }^{\circ} \mathrm{C} / \mathrm{min}$ during the test, and the heating rate during the test is stable and reliable.

The ambient temperature, the center temperature, and the reaction time of the different charge diameter samples are obtained by processing the temperature-time data obtained from the test. The response level is obtained by analyzing the state of the witness board and the test tube which are obtained from the test site after the reaction. The test status and results are shown in Table 2.

Fit the ambient temperature-charge diameter, center temperature-charge diameter when samples with different charge diameters react, and obtain the temperature change curve with charge diameter and the respective fitting curve and function relationship, as shown in Fig. 6. 
Table 2. The results of the slow cook-off test of different diameter samples (start timing when the ambient temperature reaches $20^{\circ} \mathrm{C}$ )

\begin{tabular}{|c|c|c|c|c|}
\hline $\begin{array}{c}\text { Charge diameter } \\
(\mathrm{mm})\end{array}$ & $\begin{array}{c}\text { Ambient temperature } \\
\left({ }^{\circ} \mathrm{C}\right)\end{array}$ & $\begin{array}{c}\text { Core temperature } \\
\left({ }^{\circ} \mathrm{C}\right)\end{array}$ & $\begin{array}{c}\text { Reaction time } \\
(\mathrm{min})\end{array}$ & $\begin{array}{c}\text { Response } \\
\text { level }\end{array}$ \\
\hline 20 & 230.6 & 228.4 & 212.2 & Detonation \\
\hline 60 & 238.4 & 180.1 & 217.1 & Detonation \\
\hline 97.5 & 254.2 & 155.7 & 239.7 & Detonation \\
\hline 148 & 297.4 & 115.9 & 248.5 & Detonation \\
\hline
\end{tabular}

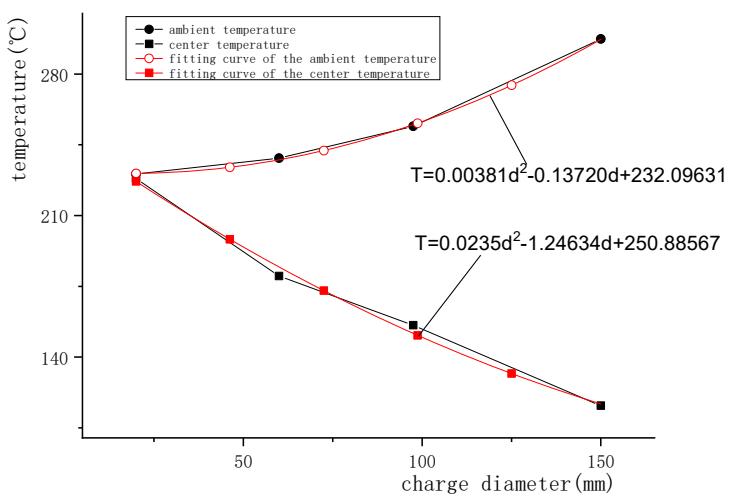

Fig. 6. Temperature-diameter curve and its fitting curve

\subsection{The effect of charge diameter on response level}

The American MIL-STD-2105D standard divides the results of the slow cook-off test into 5 levels: Type I is detonation reaction; Type II is partial detonation reaction; Type III is explosive reaction; Type IV is deflagration reaction; Type $\mathrm{V}$ is combustion reaction. At present, the severity of the reaction cannot be determined quantitatively. It can only be qualitatively evaluated by the deformation and rupture of the tube and the state of the witness plate. The states of the stent, test tube fragments and the witness plate collected after the reaction are analyzed, the different charge diameter samples are all type I detonation reactions, and the charge diameter has no significant effect on the response level of the reaction.

\subsection{The effect of the charge diameter on the ambient temperature and core temperature during the reaction}

From Table 2 and Fig. 6, it can be found that as the diameter of the charge increases, the ambient temperature when the reaction of the sample increases regularly, on the contrary the center temperature decreases regularly. The process of transferring heat from the outer surface of the sample metal tube to the inner surface and then to the sample and the center of the sample is mainly conducted by heat conduction. According to the theory of heat transfer, the heat transfer per unit time is inversely proportional to the thickness [10]. As the diameter of the charge increases, the longer it takes for the heat to be transferred from the surface of the tube to the center of the charge, so when the reaction occurs, the center temperature gradually decreases. Since the slow cook-off sample is heated at a constant heating rate, the ambient temperature when the sample reacts increases with the increase of the charge diameter. From Fig. 6, it can be found that the ambient temperature and center temperature change regularly with the charge diameter. The fitted function relationship of the ambient temperature and the center temperature with charge diameter are shown in Fig. 6. The fitted curve is in good agreement with the test curve. 


\section{Conclusions}

The slow cook-off test of cyclotetramerthylenetetranitramine based explosives with different charge diameters was carried out using the self-developed test device, and the slow cook-off performance of cyclotetramerthylenetetranitramine based explosives was obtained. The following conclusions are obtained by analyzing the results of the slow cook-off test:

1) The charge diameter has no significant effect on the response level of the slow cook-off of cyclotetramerthylenetetranitramine based explosives.

2) The ambient temperature and center temperature change regularly with the increase of the charge diameter.

3) The change of the ambient temperature and center temperature with the charge diameter conforms to the quadratic polynomial law, and the fitted curve is in good agreement with the test curve.

\section{References}

[1] Li Jinqing Evaluation method of low vulnerability explosives. Journal of Propellants, Vol. 2, 1999, p. $15-18$.

[2] Sumrall T. S. Large scale fast cook-off sensitivity results of a melt cartable general purpose insensitive high explosive. Propellants, Explosives, Pyrotechnics, Vol. 24, 1999, p. 61-64.

[3] Balas M. W., Nicolich M. S., Daniels M. A. Insensitive Monition and Warheads Performance Testing of PAX-3. Insensitive Munitions and Energetic Materials Technology Symposium, San Francisco, 2004.

[4] Han Bo, Zhang Xiaozhi, Xing Yuren A new type of propellant charge low vulnerability test research. Journal of Propellants and Explosives, Vol. 31, Issue 1, 2008, p. 53-55.

[5] Sehoites J. H G. Strain. Rate Results of the TNO-PML. Cook-off Test with HTPB/AP and PPG/AP/AN Propellants, PML1996-A87.1-17. TON Prins Maurits Laboratory, Netherland, 1997.

[6] Kondrikov B. N. Investigation of cook-off-type test methods. 11th International of Detonation Symposium, Snowmass: Snowmass Conference Center, 1998, p. 135-142.

[7] Wang Xiaofeng, Dai Ronglan, Tu Jian Burning experiment of booster. Pyrotechnics, Vol. 2, 2001, p. 5-7.

[8] Feng Changgen, Zhang Rui, Chen Lang Cook-off experiment and numerical simulation of RDX explosives. Energetic Materials, Vol. 12, Issue 4, 2004, p. 193-198.

[9] Yang Lixia, Zhang Zouzou, Liu Laidong Experimental study on vulnerability response of propellant charge under thermal stimulation. Journal of Propellants, Vol. 31, Issue 3, 2008, p. 71-74.

[10] Zhang Yi, Guo Enzhen Heat transfer. Southeast University Press, Nanjing, 2004. 